\title{
Comparison of Lumbar Lordosis in Lateral Radiographs in Standing Position with supine MR Imaging in consideration of the Sacral Slope
}

\author{
Vergleich der lumbalen Lordose im seitlichen Röntgenbild \\ im Stehen und der MRT unter besonderer \\ Berücksichtigung des „Sacral Slope“
}

Authors

Achim Benditz ${ }^{1}$, Daniel Boluki ${ }^{1}$, Markus Weber ${ }^{1}$, Florian Zeman², Joachim Grifka ${ }^{1}$, Florian Völlner ${ }^{1}$

Affiliation

1 Orthopedic Surgery, University Medical Center Regensburg, Bad Abbach/ Regensburg, Germany

2 Center for Clinical Studies, University Medical Center Regensburg, Germany

Key words

lumbar lordosis, sagittal balance, standing radiographs, supine MRI, sacral slope, lumbar spine

received 24.7.2016

accepted 14.10 .2016

Bibliography

DOI http://dx.doi.org/10.1055/s-0042-120112

Published online: 21.12.2016 | Fortschr Röntgenstr 2017; 189: 233-239

(c) Georg Thieme Verlag KG Stuttgart · New York

ISSN 1438-9029

Correspondence

Herr Dr. Achim Benditz

Department of Orthopedics I, Asklepios Medical Center

Kaiser-Karl-V.-Allee 3

93077 Bad Abbach

Germany

Tel.: ++ 49/94 05/1 80

achim.benditz@ukr.de

\section{ZUSAMMENFASSUNG}

Ziel Ziel dieser retrospektiven Studie war es, den Einfluss des „Sacral Slope“ auf den Zusammenhang zwischen der gemessenen lumbalen Lordose in lateralen Röntgenaufnahmen der Wirbelsäule im Stehen und liegenden MRT Aufnahmen zu untersuchen. Dieser Zusammenhang ist in der Literatur weitgehend unbekannt. Bisherige Studien haben Zusammenhänge für die thorakale Wirbelsäule gezeigt, jedoch nicht für die lumbalen Anteile.

Material und Methoden MRT und seitliche Röntgenbilder im Stehen von 63 Patienten ohne momentane Rückenschmerzen oder radiologischen Pathologien der Lendenwirbelsäule wurden untersucht. Die Vermessung der lateralen Röntgenaufnahmen im Stehen beinhaltete die sagittalen Parameter Pelvic Incidence (PI), Pelvic Tilt (PT) und Sacral Slope (SS); zudem wurden im Röntgen und in den MRT Aufnahmen die L1-S1 Lordose und die einzelnen Segmentlordosen gemessen. Die Unterschiede zwischen Röntgen und MRT wurden ana- lysiert und entsprechend der Roussouly Klassifikation in 4 Gruppen mit unterschiedlichem Sacral Slope unterteil.

Ergebnisse Die globale lumbale Lordose (L1-S1) war 44,99 $( \pm 10754) \mathrm{im}$ Röntgen und $47,91^{\circ}( \pm 9,170)$ im MRT. Das entspricht einer klinisch relevanten Korrelation $(r=0,61, p<0,01)$. Die Messung der Segmentlordosen zeigte nur geringe Unterschiede. Außer in L5/S1 wiesen alle Segmente eine höhere Lordose im Röntgen als im MRT auf. Der mittlere Durchschnitt der globalen Lordose L1-S1 betrug $-2,9^{\circ}$. Bezogen auf die Roussouly Gruppen zeigte sich der größte Unterschied in Gruppe 2 für L1-S1 $\left(-8,3^{\circ}\right)$. In Gruppe 4 zeigte sich im MRT eine L5/S1 Lordose von 25,71 . Diese war im Vergleich zu den anderen Gruppen nur in Gruppe 4 niedriger als die Lordose im Segment L4 / L5 $\left(27,63^{\circ}\right)$.

Schlussfolgerung Obwohl sich die globale Lordose in den beiden Bildgebungsmodalitäten signifikant unterscheidet ist die Differenz nur $2,9^{\circ}$. Liegend-MRT-Aufnahmen können zur Abschätzung der globalen Lordose verwendet werden, dienen jedoch nicht zur Beurteilung einzelner Segmentlordosen, welche daher in lateralen Röntgenaufnahmen im Stehen gemessen werden sollten.

\section{Kernaussagen}

- Im Segment L5/S1 zeigt sich ein erheblicher Unterschied in beiden Messverfahren.

- MRT Aufnahmen können verwendet werden, um die globale lumbale Lordose abzuschätzen.

- Um einzelne Segmentlordosen zu bestimmen benötigt man laterale Röntgenbilder im Stehen.

\section{ABSTRACT}

Purpose To investigate the influence of sacral slope on the correlation between measurements of lumbar lordosis obtained by standing radiographs and magnetic resonance images in supine position (MRI). Little information is available on the correlation between measurements of lumbar lordosis obtained by radiographic and MR images. Most relevant studies have shown correlations for the thoracic spine, but detailed analyses on the lumbar spine are lacking.

Methods MR images and standing lateral radiographs of 63 patients without actual low back pain or radiographic pathologies of the lumbar spine were analyzed. Standing radiographic measurements included the sagittal parameters pelvic incidence (PI) pelvic tilt (PT), and sacral slope (SS); MR images were used to additionally measure lumbar L1-S1 lordosis and single level lordosis. Differences between radiographic and MRI measurements were analyzed and divided into 4 subgroups of different sacral slope according to Roussouly's classification.

Results Global lumbar lordosis (L1-S1) was $44.99^{\circ}( \pm 10754)$ on radiographs and $47.91^{\circ}( \pm 9.170)$ on MRI, yielding a clinically relevant correlation $(r=0.61$, $p<0.01$ ). Measurements of single level lordosis only showed minor differences. At all levels except for $\mathrm{L} 5 / \mathrm{S} 1$, lordosis measured by means of standing 
radiographs was higher than that measured by MRI. The difference in global lumbar L1-S1 lordosis was $-2.9^{\circ}$. Analysis of the Roussouly groups showed the largest difference for $\mathrm{L} 1-\mathrm{S} 1\left(-8.3^{\circ}\right)$ in group 2 . In group 4 , when measured on MRI, L5 / S1 lordosis $\left(25.71^{\circ}\right)$ was lower than L4 / L5 lordosis $\left(27.63^{\circ}\right)$ compared to the other groups.

Conclusions Although measurements of global lumbar lordosis significantly differed between the two scanning technologies, the mean difference was just $2.9^{\circ}$. MRI in supine position may be used for estimating global lumbar lordosis, but single level lordosis should be determined by means of standing radiographs.

\section{Key Points}

- Large difference between radiographic and MRI measurements of level L5/S1.

- MRI can be used for estimating global lumbar lordosis.

- Analysis of single level lordosis necessitates measurement in standing radiographs.

\section{Citation Format}

- Benditz A, Boluki D, Weber M et al. Comparison of Lumbar Lordosis in Lateral Radiographs in Standing Position with supine MR Imaging in consideration of the Sacral Slope. Fortschr Röntgenstr 2017; 189: 233-239

\section{Objectives}

Analysis of sagittal balance has gained in importance, and measurement of radiographic spinopelvic parameters is now a routine part of many surgical interventions. Indeed, surgical correction of lumbar lordosis must be proportional to pelvic incidence (PI) [1, 2]. Reference data of asymptomatic patients may be helpful to understand individual disease progression, to achieve goals of movement therapies, and to improve the quality of monitoring therapies [3].

Sagittal spine geometry is position-dependent. Radiologic measurements cannot be automatically transferred from one position to another [4 -8]. Only few studies have examined positiondependent measurement or the interchangeability of radiologic technologies in lumbar spine imaging $[4,6]$. Regarding the interchangeability of CT measurements in supine position with upright conventional sagittal radiographs, CT measurements have been shown to be an inappropriate tool for baseline assessment of sagittal lordosis of the injured thoracolumbar spine if upright conventional sagittal plane radiographs are used for follow-up measurements [4]. One investigator using MRI measurements in supine position showed that lumbar lordosis visible in upright position can be reproduced by placing the patient in supine position with straightened legs [9]. Other studies have shown good correlations for Cobb angles depending on the particular curve severity in adolescent idiopathic scoliosis [10]. To our knowledge, the present study is the first to investigate the possible interchangeability of measurements of sagittal lumbar lordosis obtained by MRI in supine position and upright conventional radiographs.

The main purpose of the current study was to analyze the correlation between global lumbar lordosis and single level lordosis measured by means of both MRI in supine position and radiographs in standing position in patients without any severe back problems at the moment. We wanted to find out whether MR images in supine position could also be an alternative to radiographs in standing position as a first assessment of sagittal balance.

\section{Materials and methods}

\section{Subjects}

This retrospective study was approved by the local Ethics Committee and follows the guidelines of this journal. 276 patients were reviewed who had simultaneously undergone an MRI examination of the lumbar spine in supine position and a lateral standing radiograph of the lumbar spine with viewable femoral heads between April 2014 and March 2016 ( $\triangleright$ Table 1). The indication for imaging in our internal assessment was suspicion of rheumatological disease and history of an episode of low back pain. The following inclusion criteria applied: (1) patients with both lateral radiographs of the lumbar spine with femoral heads in standing position and lumbar spine MRI in supine position (2) aged between 30 and 85 years (patients under 30 years of age had not received a lateral radiograph). Exclusion criteria were (1) previous spinal surgery, (2) a Cobb angle of $>20^{\circ}$, (3) fracture of a vertebra, (4) acute disc herniation, (5) history of total hip replacement, (6) severe radiological pathologies of the lumbar spine, and (7) flexion contraction of the hip. Only 63 of the 276 patients reviewed could be included. Because many patients showed radiological pathologies in the MRI, the exclusion rate was rather high.

\section{Radiographic imaging}

The MRI protocol included a T2 weighted turbo spin echo sequence in sagittal orientation. All lumbar images were acquired with a 1.5 T system (Ingenia, Philips N.V., Amsterdam, The Netherlands) using a digital posterior coil. The following scan parameters were used: slice thickness, $4 \mathrm{~mm}$; repetition time (TR), $3000 \mathrm{~ms}$; echo time (TE), $100 \mathrm{~ms}$; matrix, $704 \times 704$; reconstructed voxel size, $0.43 \times 0.43 \times 4 \mathrm{~mm}$; acquired voxel size, $0.60 \times 0.86 \times 4 \mathrm{~mm}$; scan duration, 4:12 min; patients in supine position with knees $60^{\circ}$ flexed on a pillow.

All lateral radiographs of the lumbar spine were acquired in standing position with a digital flat panel detector system (Sie-

- Table 1 Demographic data of the 63 patients included.

- Tab. 1 Demografische Daten der 63 eingeschlossenen Patienten.

\begin{tabular}{|l|l|l|}
\hline & mean \pm SD & range \\
\hline age $(\mathrm{yr})$ & $62.3 \pm 7.3$ & $37-78$ \\
\hline gender (m:f) & $25: 38$ & \\
\hline $\begin{array}{l}\text { lumbar L1-S1 lordosis on } \\
\text { radiographs }\left(^{\circ}\right)\end{array}$ & $44.99 \pm 10754$ & $29-59$ \\
\hline lumbar L1-S1 lordosis on MRI $\left(^{\circ}\right)$ & $47.91 \pm 9170$ & $36-74$ \\
\hline
\end{tabular}


mens Multix Vertix, Siemens Healthcare, Erlangen, Germany). The following scan parameters were used: tube voltage, $90 \mathrm{kV}$; tube current, dose modulated; focus-to-detector distance of $130 \mathrm{~cm}$ with the left body side to the detector and arms crossed over the body, barefooted; central beam through the iliac crest.

\section{Radiographic measurements}

All radiographic and MR images were assessed by means of the Picture Archiving and Communications System workstation of our hospital (IMPAX EE, Agfa Healthcare, Bonn, Germany). All measurements were done with SurgiMap Version 1.2.1.70 [11]. On standing lateral radiographs, all single level angles were measured from the superior endplate of the upper vertebra to the inferior endplate of the lower vertebra (L1 / L2, L2 / L3, L3 / L4, L4 / L5). L5 / S1 was measured from the superior endplate L5 to the superior endplate S1. Global lumbar lordosis (L1-S1) was measured from the superior endplate L1 to the superior endplate S1. In addition, we measured the pelvic parameters pelvic incidence (PI), pelvic tilt (PT), and sacral slope (SS) [12]. On MR images in supine position, angles were measured according to the standing radiographs. We only measured one midline-copied image to make sure to always measure the same layer of an MR image. $(\triangleright$ Fig. 1a, b)

Each parameter was measured by two independent spinal surgeons, and the mean values were adapted for analysis. Radiographs and MRI scans were evaluated in random order on different days within two weeks.

\section{Statistical methods}

Statistical analysis was carried out with SPSS (IBM SPSS Statistics, Version 23.0., Armonk, NY: IBM Corp.). Metric variables were descriptively reported using means (standard deviation). We used non-parametric tests for statistical analyzes, because histograms showed that data were not normally distributed. Therefore, group comparisons were done by means of the Wilcoxon test. Accordingly, the spearman test was used for correlations. Statistical significance was set at $\mathrm{P}<0.05$.

\section{Roussouly groups}

In 2005, Roussouly analyzed anteroposterior and lateral radiographs of 160 volunteers in standardized standing position. "The volunteers were mainly medical students, physical therapists, nurses, and other allied health professionals affiliated with the medical center where the study was performed. Those patients who were free of current or historical symptoms suggestive of spinal or orthopedic disease were included in his study" [12] ( $\triangleright$ Table 1). He then analyzed the alignment of the spine and pelvis on the lateral radiographs and used a four-part classification scheme of sagittal morphology to classify each patient. In this classification, types 1 and 2 have a sacral slope $<35^{\circ}$. In type 1 , the apex of lumbar lordosis is with a short lordosis curve in $L 5$, whilst the apex in type 2 is in the center of $L 4$ with more vertebral bodies included in the lordosis curve. Type 3 has the sacral slope between $35^{\circ}$ and $45^{\circ}$, and the sacral slope in type 4 is more than $45^{\circ}$. Using Roussouly's classification, the patients in our study were divided into 4 groups depending on the sacral
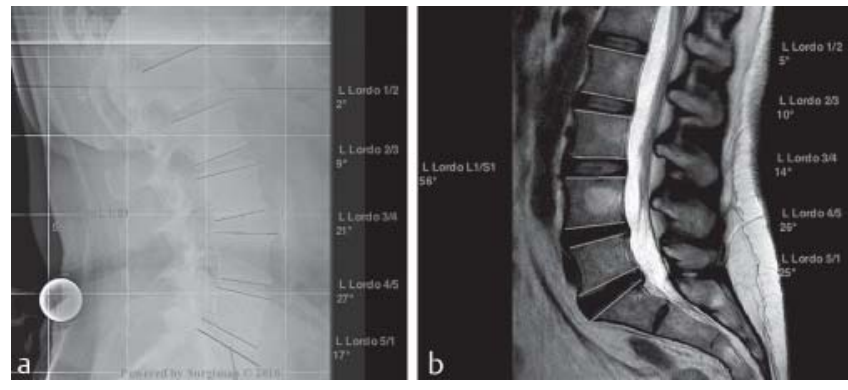

- Fig. 1 a, b Example of measuring lateral radiographs and MRI using Surgimap 2016.

- Abb. 1 a, b Beispiel der Vermessung von lateralen Röntgenbildern und MRT mit Surgimap 2016.

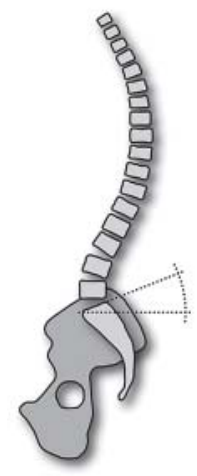

Type 1

$\mathrm{SS}<35^{\circ}$

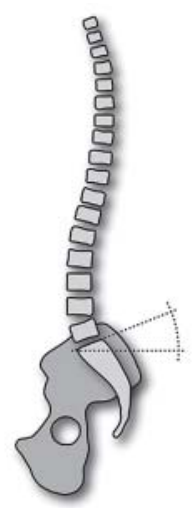

Type 2

SS $<35^{\circ}$

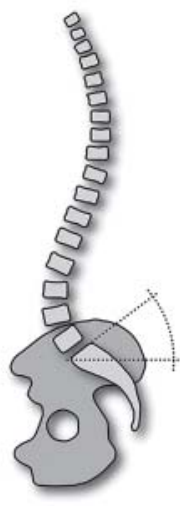

Type 3

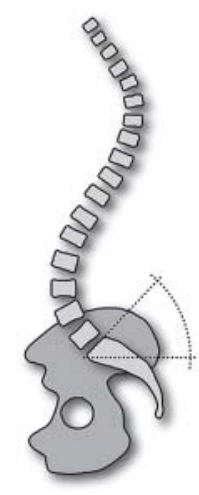

Type 4

- Fig. 24 Roussouly types of sagittal alignment (adapted from Roussouly et al., 2005 [12]).

- Abb. 2 Die 4 Typen des sagittalen Alignements nach Roussouly (angelehnt an Roussouly et al., 2005 [12]).

slope (SS): Group 1 and 2 had $\mathrm{SS}<35^{\circ}$, group 3 showed $35<$ SS $<45$, and group 4 SS $>45$ ( $\triangleright$ Fig. 2 ).

\section{Results}

\section{Total cohort}

The mean sagittal parameters of our cohort were close to that of the original Roussouly cohort of 2005 [12] ( $\triangleright$ Table 2).

On standing radiographs, global lumbar lordosis (L1-S1) was $44.99^{\circ}( \pm 10754)$ across the four Roussouly groups. On MR images in supine position, global lumbar lordosis was $47.91^{\circ}$ $( \pm 9170)$. ( $\triangleright$ Table 1$)$ Despite this significant difference $(p<0.05)$, the clinically relevant correlation was weak: $r=0.611$, $\mathrm{p}<0.01$. The mean intra-individual difference between L1-S1 on standing radiographs and on MRI in supine position was $-2.9^{\circ}$ $( \pm 9080)$. Angles on the standing radiographs ranged between $29^{\circ}$ and $59^{\circ}$ and from $36^{\circ}$ to $78^{\circ}$ on the MRI. Analyses of each single level showed increases in mean lordosis from L1 / L2 to L4 / L5 on both technologies (radiographs $5.25^{\circ}-22.54^{\circ}$, MRI $3.98^{\circ}-$ 
- Table 2 Comparison of the mean sagittal parameters between the original Roussouly [Roussouly 2005] cohort and our cohort.

- Tab. 2 Vergleich der durchschnittlichen sagittalen Parameter zwischen der originalen Roussouly Kohorte [Roussouly 2005] und unsere Kohorte.

\begin{tabular}{|l|l|l|}
\hline parameter & $\begin{array}{l}\text { roussouly } \\
\text { cohort } \mathbf{n}=\mathbf{1 6 0} \\
\left(\text { mean }^{\circ} \pm \text { SD) }\right.\end{array}$ & $\begin{array}{l}\text { our cohort } \mathbf{n}=\mathbf{6 3} \\
\left(\text { mean }^{\circ} \pm \text { SD) }\right.\end{array}$ \\
\hline pelvic incidence (PI) & $51.91 \pm 10.71$ & $55.90 \pm 11.05$ \\
\hline sacral slope (SS) & $39.92 \pm 8.17$ & $34.29 \pm 8.81$ \\
\hline pelvic tilt (PT) & $11.99 \pm 6.46$ & $21.00 \pm 6.35$ \\
\hline
\end{tabular}

$\left.21.30^{\circ}\right)$. Level L5 / S1 showed highly interesting values: angles on the radiographs had decreased to $14.83^{\circ}( \pm 7600)$ but increased to the highest lumbar value of $25.04^{\circ}( \pm 3925)$ on the MRI. Therefore, the differences between radiographic and MR image were slightly positive in the upper lumbar spine but had decreased to negative values in the lower lumbar spine ( $\triangleright$ Fig. 3 ). The correlation $\mathrm{R}$ was 0.611 .

\section{Findings in Roussouly group 1}

18 patients were assigned to group 1. Lumbar L1-S1 lordosis on the radiographs was $39.14^{\circ}( \pm 9465)$ and $42.53^{\circ}( \pm 6326)$ on the MRI, thus somewhat less than in the total cohort for both technologies ( $\vee$ Fig. 4 ). These values presented the best and clinically most significant correlation of all groups $R=0.707,(p<0.01)$ that was even higher than the correlation in the total cohort. Values of the single level analysis also corresponded with the findings of the total cohort $(\triangleright$ Fig. 5). The mean intra-individual difference between L1-S1 on standing radiographs and MRI in supine position was $-3.39^{\circ}( \pm 6.11)$ ( Fig. 6). In this group, L5/S1 lordosis measured by means of MRI was so high that even global lordosis was higher on MRI than on the radiograph ( $\mathbf{F i g . 6}$ ).

\section{Findings in Roussouly group 2}

14 patients were assigned to group 2. Lumbar L1-S1 lordosis on the radiographs was $36.96^{\circ}( \pm 4826)$ and $45.29^{\circ}( \pm 5539)$ on the MRI ( $\triangleright$ Fig. 6). This finding was the largest intra-individual difference between L1-S1 on standing radiographs and the MRI in supine position of all groups, $-83214^{\circ}( \pm 5276)$. For level L5/S1, group 2 was the only one showing a significant difference $(p<0.001)$ ( $\triangleright$ Fig. 6); level L4 / L5 showed the nearly the same values on both technologies (radiograph $19.82^{\circ}$ and MRI $19.61^{\circ}$ ). All other groups showed higher angles for L4 / L5 on the radiographic than on the MR images.

\section{Findings in Roussouly group 3}

Group 3 included 19 patients. Lumbar L1-S1 lordosis on the radiographs was $53.87^{\circ}( \pm 7308)$ and $51.63^{\circ}( \pm 11040)$ on the MRI. This value was the highest of all groups and higher than the radiographic value for the total cohort ( $\vee$ Fig. 4$)$. Although the mean difference was only $2237^{\circ}( \pm 11029)$, there was no correlation $(R=0.167)(\triangleright$ Fig. 6). Group 3 was also the only group with a

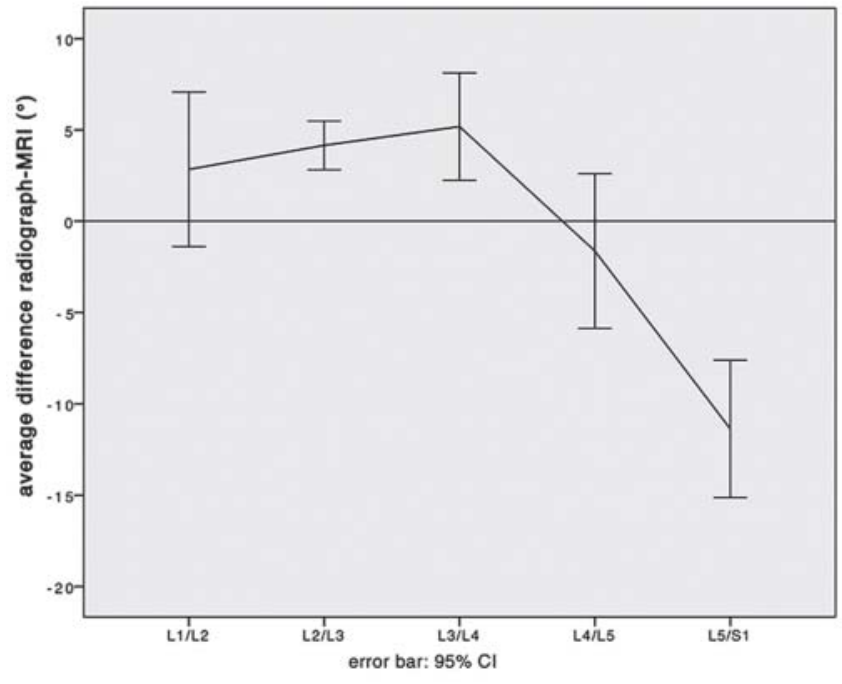

- Fig. 3 Difference of lumbar lordosis between radiographic and MR images at every single lumbar level; in the upper lumbar spine, segmental lordosis is increased in the standing $\mathrm{x}$-ray; in the two lower levels, especially at L5/S1, segmental lordosis is much more pronounced on the MRI in supine position than on the x-ray.

- Abb. 3 Unterschied der lumbalen Lordose zwischen Röntgenbildern und MRT in jedem lumbalen Wirbelsäulensegment; die lumbale Segmentlordose in der oberen LWS ist in den stehenden Röntgenaufnahmen erhöht; in den zwei unteren Segmenten, ist die Lordose besonders in L5 / S1 im MRT deutlich höher als im Röntgen.

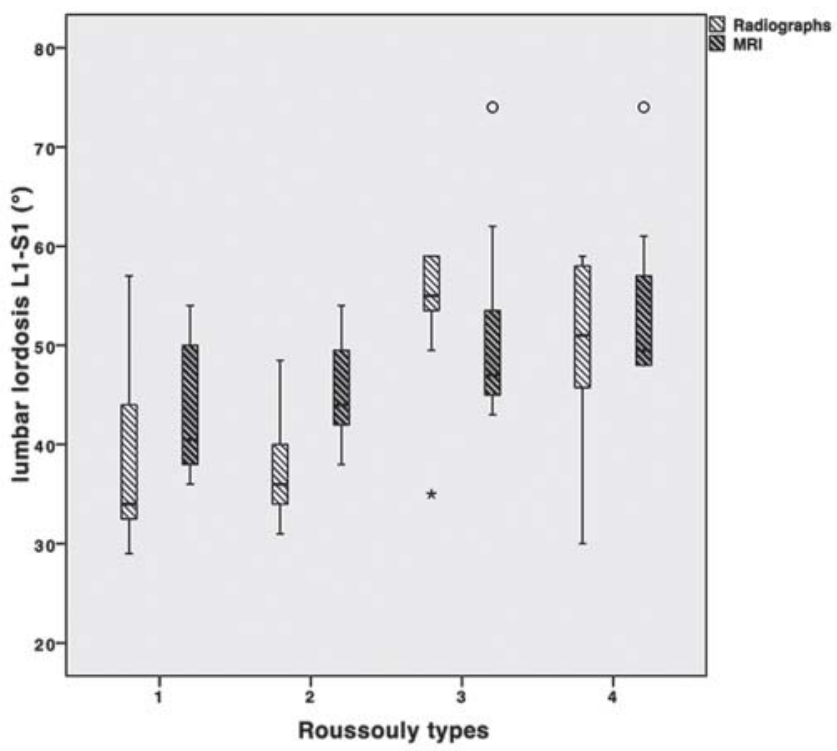

- Fig. 4 Comparison of lumbar L5 / S1 lordosis measured by radiographic and MR images for each Roussouly group.

- Abb. 4 Vergleich der Lordose im Segment L5/S1 im Röntgen und MRT bezogen auf die einzelnen Roussouly Gruppen.

higher value for L1-S1 lordosis on radiographs than on MRI. Values for single level lordosis on radiographs were higher in the upper levels than those in other groups ( $\triangleright$ Fig. 5). 


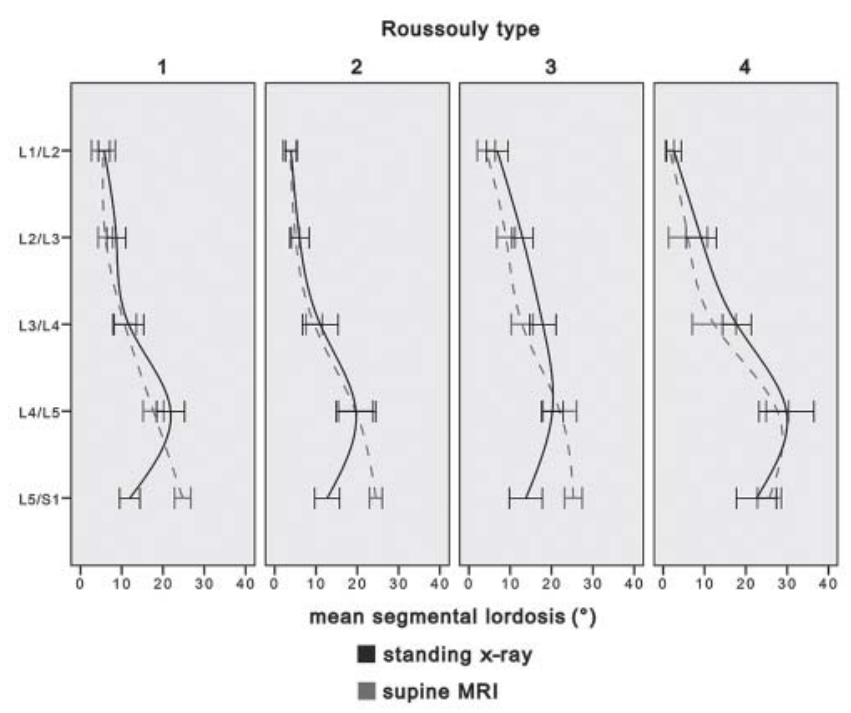

error bar: $95 \% \mathrm{Cl}$

- Fig. 5 Mean single level lordosis of the four Roussouly types measured by means of radiographs (black) and MRI (red).

- Abb. 5 Durchschnittliche Segmentlordose für die vier Roussouly Gruppen im Röntgen (schwarz) und im MRT (rot).

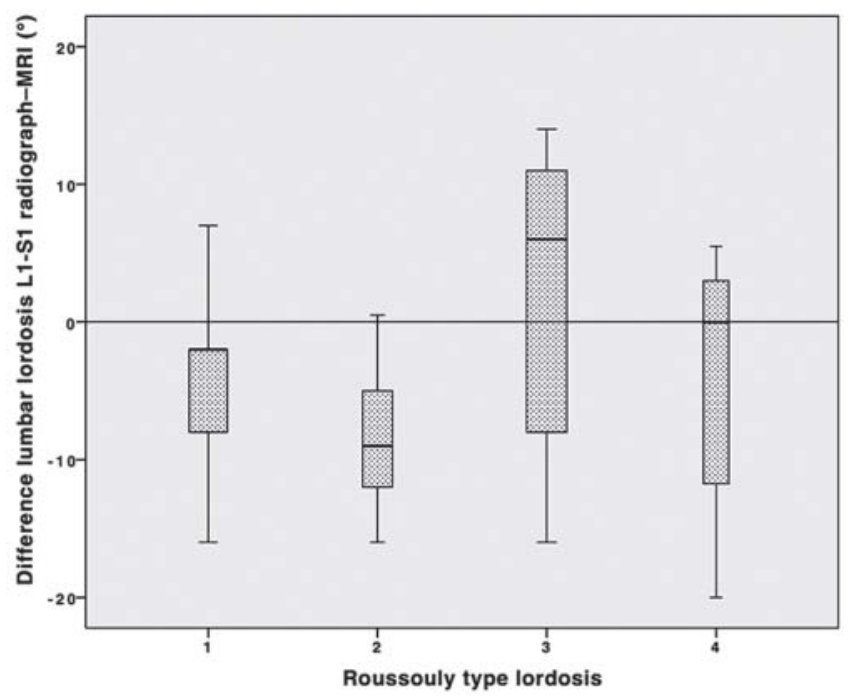

- Fig. 6 Difference in lumbar L1-S1 lordosis measured by radiographic and MR images according to Roussouly types; in type 1, 2 and 4 , lordosis in $\mathrm{x}$-ray is higher than that on MRI; in type 3 , lordosis is higher in standing position. The largest mean difference with $8.3^{\circ}$ is found in type 3 .

- Abb. 6 Unterschiede der Lordose L1-S1 im Röntgen und MRT bezogen auf die Roussouly Typen; bei Typ 1, 2 und 4 ist die Lordose im Röntgen mehr als im MRT; bei Typ 3 ist die Lordose im stehenden Röntgen höher. Den größten durchschnittlichen Unterschied mit $8,3^{\circ}$ sieht man bei Typ 3 .

\section{Findings in Roussouly group 4}

12 patients were assigned to group 4. Lumbar L1-S1 lordosis on the radiographs was $49.08^{\circ}( \pm 10297)$ and $53.17^{\circ}( \pm 8133)$ on the MRI, which was the highest value of all MRI measurements ( $\triangleright$ Fig. 4). The mean intra-individual difference between L1-S1 on standing radiographs and MRI in supine position was $-40833^{\circ}$ $( \pm 9449)$ ( $\triangleright$ Fig. 6$)$. This finding was not significant and had no correlation. In group 4, L5/S1 lordosis $\left(25.71^{\circ}\right)$ on MRI was decreased in comparison to L4 / L5 lordosis $\left(27.63^{\circ}\right)$. In the other groups, this finding was only seen on the radiographs but not on the MRI. With regard to the other levels, the findings corresponded to those of the other groups ( $\triangleright$ Fig. 5).

\section{Discussion}

Evaluating sagittal balance has become more and more important in the treatment of low back pain and in planning surgical procedures [1, 2, 13-15]. No study has yet really addressed the use of MRI with regard to sagittal profile measurement of the lumbar spine with regard to differences in single levels in consideration of the Roussouly classification of different types of sacral slope [12]. In this study, we investigated the influence of sacral slope on the correlation between measurements of lumbar lordosis obtained by standing radiographs and MRI in supine position.

Previous studies have investigated thoracic kyphosis and - as control - lumbar lordosis using MR images in supine position to evaluate the coronal Cobb angle [16-20].

Inter-observer reliability was higher in MRI than in X-ray measurements, which may lead to the conclusion that MR images can be measured more precisely [19]. However, we only measured one midline-copied image to make sure to always measure the same layer of an MR image. The main problem of MRI examinations is the supine position, which eliminates the effect of gravity. All patients undergoing MRI in supine position had a $60^{\circ}$-angle pillow under their knees to make lying on the back more comfortable. A recent study has shown a higher degree of slippage in symptomatic patients with spondylolisthesis in supine magnetic resonance imaging with straightened lower extremities than in conventional MRI with flexed lower extremities[21]. Changes in lumbar lordosis due to knee flexion have been controversially discussed in the literature. The best comparison we have found are changes in lumbar lordosis when wearing high-heels, which increases knee flexion. For such cases, some authors described decreased lumbar lordosis in comparison to the normal standing position [22-24]; others found increased lumbar lordosis, and several authors did not find any differences [25, 26]. However, none of these authors had considered the different Roussouly types or single level lordosis. Therefore, our finding that lumbar lordosis slightly increased in groups 1, 2, and 4 and decreased in group 3 corresponded with the literature [16-19]. We also found these effects at each single level, except for level L5/S1, which showed a reversed effect. This effect was so great that it also influenced the measurement of global lumbar L1-S1 lordosis. Thus, we found a slightly greater level of lordosis on the MRI than on the radiograph. We have no direct anatomic explanation for this fact, but $60^{\circ}$ knee flexion may have this reverse effect on L5/S1. 
In clinical practice, healthy patients could undergo an MRI in supine position to avoid unnecessary exposure to radiation [27, 28], if only the level of global lumbar lordosis needs to be assessed as a first planning of conservative treatment of low back pain. If further information should be required, particularly single level angles, for instance when planning a surgical procedure such as spinal fusion [29, 30], the two scanning technologies should be used simultaneously because of their increasing differences between upper and lower spinal levels.

Our data analysis according to the four Roussouly groups [12] also showed some differences in the single levels. In group 1 , "the sacral slope is less than $35^{\circ}$, and the apex of lumbar lordosis is the center of the L5 body." Roussouly described the lower arc of lordosis as minimal [12]. In comparison, group 2 "has the apex in body L4." The radiographs in our study showed the same findings: i. e., the angle L4/5 was higher in group 1 than in group 2. Group 1 had the best correlation between MRI and radiograph measurements.

In group 3, "the apex of lumbar lordosis is in the center of the L4 vertebral body. The lower arc of lordosis becomes more prominent." [12] In group 4, "the apex of the lumbar lordosis is located at the base of the $L 3$ vertebral body or higher." Our radiographs had the highest angles of all groups at L3/4 and accordingly in group 3 that also showed a higher angle at L2/3. Because group 3 showed such high levels of lordosis at L2 / L3 and L3/4 on the radiographs so that also L1-S1 lordosis was still higher than that measured by means of MRI in supine position, we obtained the presumed result with a smaller angle for L1-S1 on MRI.

The major limitation of the present study is the uncertainty of distinguishing between the effects of body position within one radiologic technology or between the two different technologies using the same body position. Another limitation is the retrospective approach. Although our scanning modalities are usually standardized, correct positioning of the patient cannot be guaranteed retrospectively. Additionally, our patients had no severe back problems but only minor disc degeneration. In the case of more degenerative discs, the stability of the spine may be influenced, which could result in higher differences. Therefore, further studies with the same design but using degenerated discs or degenerated spondylolisthesis are recommended.

\section{Conclusion}

Although the two scanning technologies investigated showed a significant difference in global lumbar lordosis, the mean difference was just $2.9^{\circ}$. Thus, there was only a clinically weak correlation for global lumbar lordosis. That means MRI in supine position may be used for estimating global lumbar lordosis as required, for instance to indicate conservative treatment options for low back pain as a first approach. Analysis of single level lordosis, for example for planning surgical fusion, necessitates radiographs in standing position, particularly of the lower lumbar spine.

\section{References}

[1] Huec J, Aunoble S, Philippe L et al. Pelvic parameters: Origin and significance. Eur Spine J 2011; 20 (Suppl. 5): 564-571

[2] Le Huec J], Roussouly P. Sagittal spino-pelvic balance is a crucial analysis for normal and degenerative spine. Eur spine J September 2011; 20 (Suppl. 5): 556-557

[3] Schröder J, Braumann KM, Reer R. Spinal form and function profile: Reference values for clinical use in low back pain. Orthopade 2014; 43: $841-849$

[4] Bouaicha S, Lamanna C, Jentzsch T et al. Comparison of the sagittal spine lordosis by supine computed tomography and upright conventional radiographs in patients with spinal trauma. Biomed Res Int 2014; 2014: 967178

[5] Wood KB, Kos P, Schendel M et al. Effect of patient position on the sagittal-plane profile of the thoracolumbar spine. J Spinal Disord 1996; 9: $165-169$

[6] Andreasen ML, Langhoff L, Jensen TS et al. Reproduction of the lumbar lordosis: A comparison of standing radiographs versus supine magnetic resonance imaging obtained with straightened lower extremities. J Manipulative Physiol Ther 2007; 30: 26 - 30

[7] Peterson MD, Nelson LM, McManus AC et al. The effect of operative position on lumbar lordosis. A radiographic study of patients under anesthesia in the prone and 90-90 positions. Spine (Phila Pa 1976) 1995; 20: $1419-$ 1424

[8] Mauch F, Jung C, Huth J et al. Changes in the lumbar spine of athletes from supine to the true-standing position in magnetic resonance imaging. Spine (Phila Pa 1976) 2010; 35: $1002-1007$

[9] Andreasen ML, Langhoff L, Jensen TS et al. Reproduction of the lumbar lordosis: A comparison of standing radiographs versus supine magnetic resonance imaging obtained with straightened lower extremities. J Manipulative Physiol Ther 2007; 30: 26 - 30

[10] Shi B, Mao S, Wang Z et al. How does the supine MRI correlate with standing radiographs of different curve severity in adolescent idiopathic scoliosis?. Spine (Phila Pa 1976) 2015; 40: 1206-1212

[11] Lafage R, Ferrero E, Henry JK et al. Validation of a new computer-assisted tool to measure spino-pelvic parameters. Spine J 2015; 15: 2493-2502

[12] Roussouly P, Gollogly S, Berthonnaud E et al. Classification of the normal variation in the sagittal alignment of the human lumbar spine and pelvis in the standing position. Spine (Phila Pa 1976) 2005; 30: 346-353

[13] Huec J, Charosky S, Barrey C et al. Sagittal imbalance cascade for simple degenerative spine and consequences: Algorithm of decision for appropriate treatment. European Spine Journal 2011; 20 (Suppl. 5): 699-703

[14] Barrey C, Roussouly P, Perrin G et al. Sagittal balance disorders in severe degenerative spine. Can we identify the compensatory mechanisms?. Eur Spine J 2011; 20 (Suppl. 5): 626-633

[15] Farshad-Amacker NA, Farshad M, Winklehner A et al. MR imaging of degenerative disc disease. Eur J Radiol 2015; 84: 1768-1776

[16] Lee MC, Solomito M, Patel A. Supine magnetic resonance imaging cobb measurements for idiopathic scoliosis are linearly related to measurements from standing plain radiographs. Spine (Phila Pa 1976) 2013; 38 : E656-E661

[17] Wessberg P, Danielson BI, Willén J. Comparison of cobb angles in idiopathic scoliosis on standing radiographs and supine axially loaded MRI. Spine (Phila Pa 1976) 2006; 31: 3039-3044

[18] Wang F, Sun X, Mao $S$ et al. MR imaging may serve as a valid alternative to standing radiography in evaluating the sagittal alignment of the upper thoracic spine. J Spinal Disord Tech 2013; 11: 582-585

[19] Bernstein P, Hentschel S, Platzek I et al. The assessment of the postoperative spinal alignment: MRI adds up on accuracy. Eur Spine J 2012; 21: $733-738$

[20] Cheung K, Karppinen J, Chan D et al. Prevalence and pattern of lumbar magnetic resonance imaging changes in a population study of one thousand forty-three individuals. Spine (Phila Pa 1976) 2009; 34: $934-$ 940

[21] Daghighi MH, Poureisa M, Arablou F et al. Supine spinal magnetic resonance imaging with straightened lower extremities in spondylolisthesis: 
A comparison with the conventional technique. Eur J Radiol 2015; 84: 921-926

[22] Franklin ME, Chenier TC, Brauninger $L$ et al. Effect of positive heel inclination on posture. J Orthop Sports Phys Ther 1995; 21: 94-99

[23] Opila KA, Wagner SS, Schiowitz S et al. Postural alignment in barefoot and high-heeled stance. Spine (Phila Pa 1976) 1988; 13: 542-547

[24] Bendix T, Sørensen SS, Klausen K. Lumbar curve, trunk muscles, and line of gravity with different heel heights. Spine (Phila Pa 1976) 1984; 9: 223-227

[25] Russell BS, Muhlenkamp KA, Hoiriis KT et al. Measurement of lumbar lordosis in static standing posture with and without high-heeled shoes. I Chiropr Med 2012; 11: 145-153

[26] de Lateur B], Giaconi RM, Questad K et al. Footwear and posture. Compensatory strategies for heel height. Am J Phys Med Rehabil 1991; 70: $246-254$
[27] Schäfer S, Alejandre-Lafont E, Schmidt T et al. Dose management for $x$ ray and CT: Systematic comparison of exposition values from two institutes to diagnostic reference levels and use of results for optimisation of exposition. Rofo 2014; 186: $785-794$

[28] Kloth JK, Wiedenhoefer B, Stiller W et al. Modern digital plain-radiography of the whole spine in scoliosis patients-dose reduction and quality criteria. Rofo 2013; 185: 48-54

[29] Rutherford EE, Tarplett LJ, Davies EM et al. Lumbar spine fusion and stabilization: Hardware, techniques, and imaging appearances. Radiographics 2007; 27: 1737-1749

[30] Ha AS, Petscavage-Thomas JM. Imaging of current spinal hardware: Lumbar spine. Am J Roentgenol 2014; 203: 573-581 